\title{
Endoscopic removal of a migrated intrauterine contraceptive device in the rectum assisted by Overstitch defect closure
}

The intrauterine device (IUD) is one of the most commonly used reversible contraception products in the word. Perforation and migration are serious complications associated with IUD insertion. The migrated IUDs can be removed by colonoscopy when a part of the IUD is visible intraluminally; however, they should be retrieved by laparoscopy and open surgery in difficult cases [1-3].

A 30-year-old woman presented with lower abdominal pain of 10-month's duration. She had had an MCu IUD, an intrauterine contraceptive device used in China, inserted in the immediate postpartum period 4 years previously but had then been lost to follow-up. Gynecological B-ultrasound showed an irregular liquid dark area, $10 \mathrm{~mm}$ deep, with poor internal sound transmission ( $\mathbf{F i g} \mathbf{1}$ a). A pelvic computed tomography (CT) scan showed that the position of the IUD had moved downwards and it was located in the cervix ( $\triangleright$ Fig. $1 \mathbf{b}$ ). On vaginal examination it was possible to touch an irregular foreign body in the upper right posterior wall of the vagina, but it was attached to the rectum, and on digital rectal examination the irregular foreign body could be felt in the rectum.

Colonoscopy showed that the mucosa was slightly gathered on the posterior wall approximately $5 \mathrm{~cm}$ from the anus (• Fig.1c). Endoscopic ultrasound (EUS) showed a strip of high echogenic shadow at the posterior wall ( $\triangleright$ Fig.1d). A KD650Q knife was used to cut into the mucosa of the lesion and it was gradually separated ( Fig.2a). After the surface mucosa had been lifted by an endoloop, the separation process was continued until the IUD was exposed and could be removed by foreign body forceps ( $\vee$ Fig. 2b,c). Finally, the mucosal defect was closed with an Overstitch suture ( $\triangleright$ Fig. 2d,e).

The post-procedure period was uneventful. The patient remained pain free throughout the follow-up period of 4

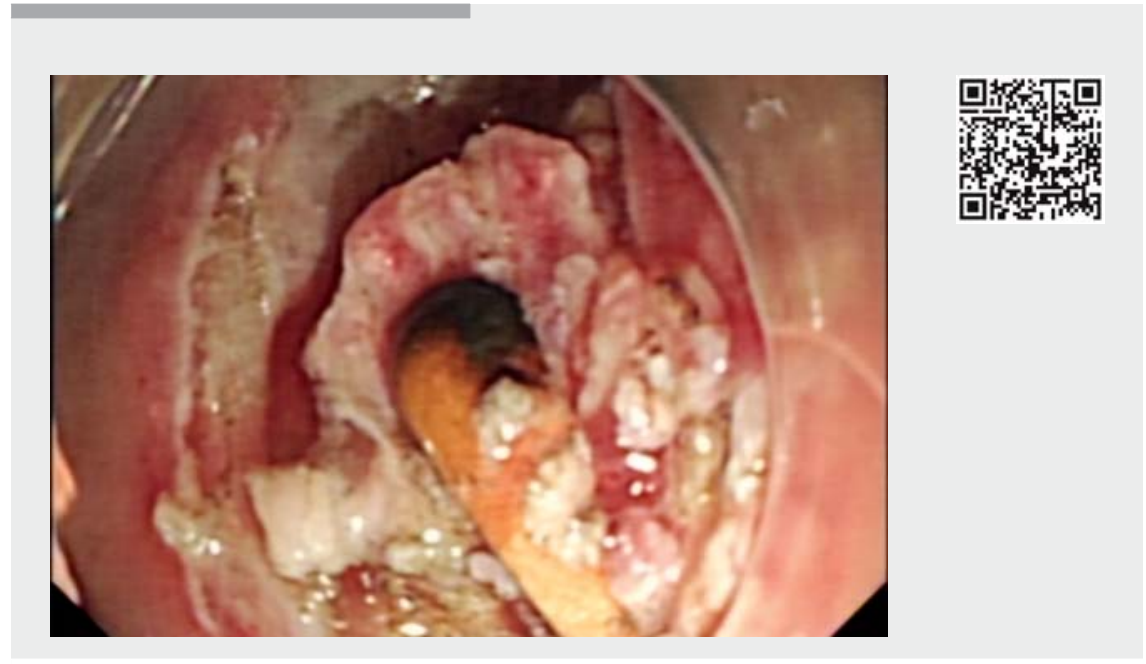

Video 1 Endoscopic removal of an intrauterine contraceptive device that had migrated into the rectum, assisted by Overstitch defect closure.
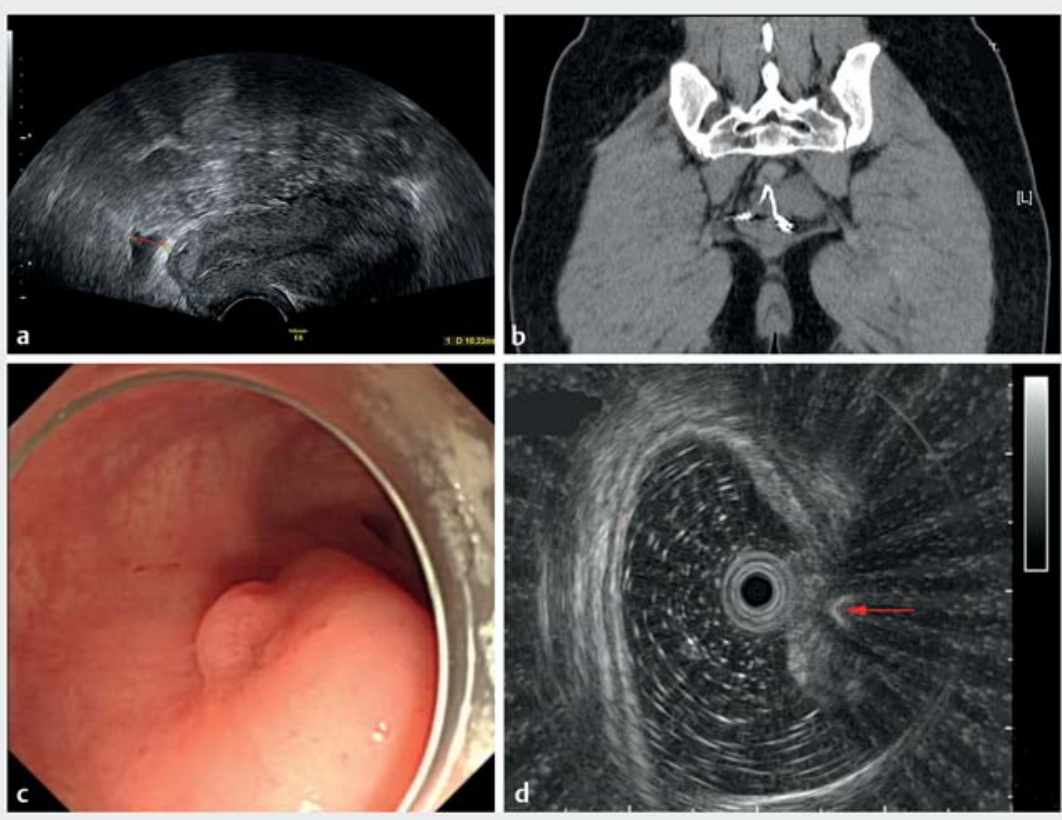

- Fig. 1 Images of an intrauterine device (IUD) that had migrated into the rectum. a Gynecological B-ultrasound image showing an irregular liquid dark area. b Pelvic computed tomography image showing the IUD in the cervix. c Colonoscopy image showing a slightly gathered mucosa on the posterior wall. $\mathbf{d}$ Endoscopic ultrasound view showing a strip of high echogenic shadow. 


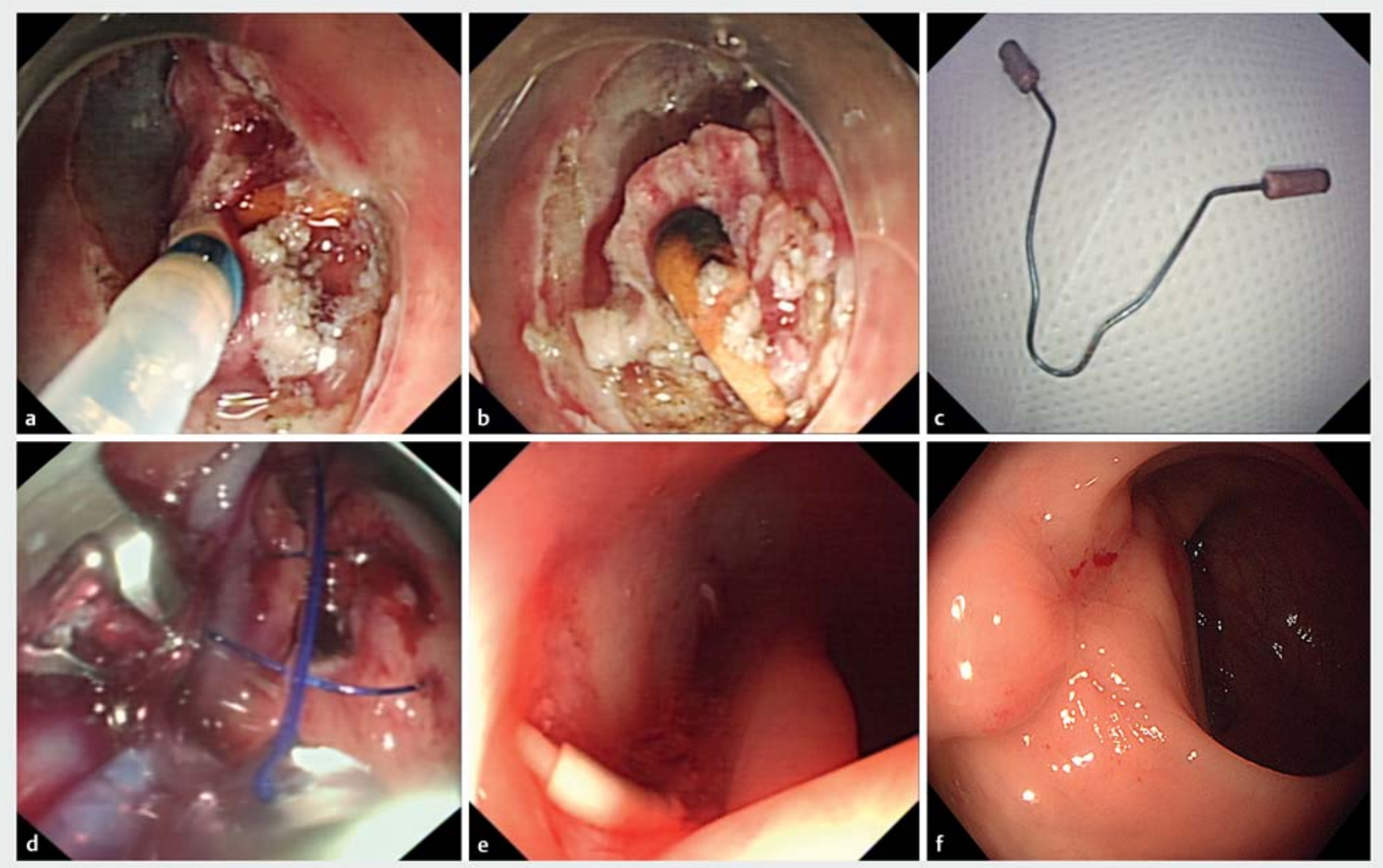

- Fig. 2 Endoscopic removal of the migrated intrauterine device (IUD). a The mucosa was separated using a KD-650Q knife; $\mathbf{b}$ the IUD was exposed and; $\mathbf{c}$ removed from the patient. $\mathbf{d}$, e The mucosal defect was closed using an Overstitch suture. $\mathbf{f}$ Repeat colonoscopy 4 weeks later showed mucosal healing.

weeks. A repeat colonoscopy performed 4 weeks after the treatment revealed complete mucosal healing ( $\mathbf{F i g} . \mathbf{2 f}$ ).

Endoscopy_UCTN_Code_CPL_1AN_2AG

\section{Competing interests}

None

The authors

Lei Peng', ", Shuchun Wei ${ }^{1}$, Xuan Li ${ }^{1}$, Duochen Jin', Huaiming Sang', Huihua Dai ${ }^{2,}{ }^{1}$, Guoxin Zhang'

1 Department of Gastroenterology, First Affiliated Hospital of Nanjing Medical University, Nanjing, China

2 Department of Gynecology, First Affiliated Hospital of Nanjing Medical University, Nanjing, China

\footnotetext{
* These authors contributed equally
}

Corresponding author

\section{Guoxin Zhang, MD}

Department of Gastroenterology, First Affiliated Hospital of Nanjing Medical University, Nanjing, China

Fax: +86-025-83714511

guoxinz@njmu.edu.cn

\section{References}

[1] Ye H, Huang S, Zhou Q et al. Migration of a foreign body to the rectum: A case report and literature review. Medicine (Baltimore) 2018; 97: e11512

[2] Chandrasekar TS, Gokul B], Yogesh KR et al. A new endoscopic method of retrieval of a migrated and transmurally embedded intrauterine contraceptive device in the rectum. Indian J Gastroenterol 2016; 35: 489 491

[3] Nair KV. Image of the month: endoscopic removal of an IUCD migrated into the rectum. Am J Gastroenterol 2016; 111: 309

\section{Bibliography}

DOI https://doi.org/10.1055/a-0884-2832

Published online: 16.5.2019

Endoscopy 2019; 51: E276-E277

(c) Georg Thieme Verlag KG

Stuttgart · New York

ISSN 0013-726X

\section{ENDOSCOPY E-VIDEOS}

https://eref.thieme.de/e-videos

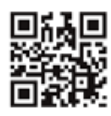

Endoscopy E-Videos is a free access online section, reporting on interesting cases and new techniques in gastroenterological endoscopy. All papers include a high quality video and all contributions are freely accessible online.

This section has its own submission website at https://mc.manuscriptcentral.com/e-videos 